\title{
EVALUASI KERASIONALAN PENGGUNAAN OBAT ANTIHIPERTENSI PADA PASIEN HIPERTENSI DI INSTALASI RAWAT INAP RSUD SULTAN IMANUDDIN PANGKALAN BUN 2018
}

\author{
Mila $^{1}$; Yogie Irawan ${ }^{2}$; Fakhruddin $^{3}$ \\ ${ }^{1,2,3,}$ STIKES Borneo Cendekia Medika Pangkalan Bun \\ ${ }^{1}$ Email : millastwan@gmail.com
}

\begin{abstract}
ABSTRAK
Pendahuluan: Hipertensi secara umum dikenal sebagai penyakit kardiovaskuler yang ditandai dengan peningkatan tekanan darah melebihi batas normal yaitu $120 / 80 \mathrm{mmHg}$. Penggunaan obat rasional merupakan penggunaan obat yang disesuaikan dengan kebutuhan klinis pasien serta dengan biaya yang paling rendah. Tujuan dari penelitian ini untuk mengidentifikasi karateristik pasien hipertensi dan kerasionalan penggunaan obat antihipertensi ditinjau dari apsek tepat pasien, tepat indikasi, tepat obat dan tepat dosis pada pasien hipertensi di instalasi rawat inap RSUD Sultan Imanuddin Pangkalan Bun periode Januari sampai Desember 2018.

Metode: Penelitian ini merupakan penelitian deskriptif dengan pengambilan data secara retrospektif yang didasarkan pada 85 rekam medik pasien hipertensi. Metode pengambilan sampel yang digunakan yaitu Purposive Sampling. Data-data yang diperoleh kemudian dibandingkan dengan menggunakan Guideline Joint National Committee (JNC) VII dan JNC VIII serta Guideline European Society Of Cardiology (ESC)/European Society Of Hypertension (ESH).

Hasil: Penelitian ini menunjukkan pasien hipertensi di Instalasi Rawat Inap RSUD Sultan Imanuddin Pangkalan Bun sebagian besar adalah perempuan (76,5\%), Usia 46-55 tahun $(41,2 \%)$, Penyakit dengan komplikasi Diabetes mellitus sebanyak 29 pasien $(22,3 \%)$, jenis hipertensi primer sebanyak 85 pasien $(100 \%)$ serta Golongan obat yang paling banyak digunakan untuk pasien hipertensi adalah Golongan ARB yaitu candesartan (49\%). Untuk evaluasi kerasionalan pengguaan obat antihipertensi dilihat berdasarkan kriteria tepat pasien sebanyak 80 pasien $(94,1 \%)$, tepat indikasi sebanyak 85 pasien $(100 \%)$, tepat obat sebanyak 83 pasien (98\%) dan tepat dosis sebanyak 85 pasien (100\%).

Kesimpulan: Penggunaan obat antihipertensi di Instalasi Rawat Inap RSUD Sultan Imanuddin Pangkalan Bun sesuai berdasarkan pedoman JNC VIII dan ESC/ESH.

Kata kunci: Hipertensi, Antihipertensi, Evaluasi kerasionalan
\end{abstract}

\section{ABSTRACT}

Introduction: Hypertension is cardiovascular disease characterized by an increase in blood pressure beyond normal limits $(120 / 80 \mathrm{mmHg})$. The rational drug use means that patient 
receiving appropriate drugs to clinical needs at the lowest cost. This study aimed to identify the characteristics of hypertension patients and the rational use of antihypertensive drugs in terms of the right patient, right indication, right medication, and right dose toward hypertension patients in inpatient installation of Sultan Imanuddin Hospital Pangkalan Bun from January to December 2018.

Methods: The study was conducted retrospectively based on 85 medical records of hypertension patients obtained using purposive sampling method. Then, the data were compared using the Guideline Joint National Committee (JNC) VII and JNC VIII and the European Society of Cardiology (ESC) / European Society of Hypertension (ESH) Guideline.

Results: The results of the study showed that the highest number of hypertensive patient were women $(76.5 \%)$, 46-55 years old $(41.2 \%)$, hypertensive with diabetes mellitus complications $(22.3 \%)$, and the primary hypertension type $(100 \%)$. The drug that most widely used was the ARB group, namely candesartan (49\%). For the evaluation of the rational use of antihypertensive drugs were right patient (94.1\%), right indication (100\%), right medication (98\%), and right dose (100\%).

Conclusion: The usage of antihypertensive drugs in this study was in accordance with the JNC VIII and ESC / ESH guidelines.

Key words: Hypertension, Antihypertensive, rational evaluation

\section{PENDAHULUAN}

Hipertensi merupakan salah satu faktor risiko utama penyebab kematian nomor satu di dunia. Secara nasional, hipertensi menjadi penyebab kematian nomor tiga stroke dan tuberculosis, mencapai $6,7 \%$ (Natalia et al, 2014). Hipertensi atau tekanan darah tinggi merupakan kondisi yang paling umum terjadi pada orang dewasa dibandingkan dengan masalah kesehatan lainnya dan merupakan faktor resiko dari penyakit kardivaskular (Porth dalam Yosida, 2016). Penggunaan obat antihipertensi yang tidak tepat dapat menyebabkan spektrum toksisitas, kegagalan terapi pengobatan, biaya pengobatan yang tinggi, komplikasi hingga kematian pasien, serta menghambat mutu pelayanan kesehatan itu sendiri. Antihipertensi senantiasa dilakukan sesuai standar, hal ini harus diterapkan di seluruh pelayanan kesehatan yang terdapat di Indonesia (Luh Sonya dkk, 2016). Penggunaan obat rasional adalah penggunaan obat yang disesuaikan dengan kebutuhan klinis pasien, baik dalam jumlah maupun waktu yang memadai, disertai dengan biaya yang paling rendah (Cippole dkk, 2012).

Profil data kesehatan di Indonesia pada tahun 2013 menyebutkan bahwa secara rasional terjadi peningkatan prevalensi hipertensi dari 7,6\% pada tahun 2007 menjadi $9,5 \%$ pada tahun 2013. Kasus hipertensi diprediksi lebih banyak terjadi pada negara berkembang yang berpenghasilan sedang sampai rendah dan Prevalensi hipertensi diperkirakan akan terus meningkat. Hal ini menandakan satu dari tiga orang menderita hipertensi. Sedangkan di Indonesia cukup tinggi, yaitu mencapai $32 \%$ dari total jumlah penduduk (Widiyani, 2013). Berdasarkan data badan pusat statistik tahun 2013 jumlah pederita hipertensi di Provinsi Kalimantan Tengah mencapai 26,7\%. Menurut data Badan 
Pusat Statistik tahun 2016 prevalensi 10 penyakit hipertensi terbesar di Kabupaten Kotawaringin Barat sebanyak 889 kasus. Sedangkan data 10 penyakit terbesar di RSUD Sultan Imanuddin

Pangkalan Bun tahun 2018 penyakit hipertensi masuk dalam urutan ke lima dengan jumlah sebanyak 585 pasien.

Penelitian ini bertujuan untuk mengidentifikasi karateristik pasien hipertensi dan kerasionalan penggunaan obat antihipertensi pada pasien hipertensi di instalasi rawat inap RSUD Sultan Imanuddin Pangkalan Bun periode Januari sampai Desember 2018.

\section{METODE PENELITIAN}

\section{Tempat dan waktu penelitian}

Penelitian ini dilaksanakann di Ruang Rekam Medik RSUD Sultan Imanuddin Pangkalan Bun Kabupaten Kotawaringin Barat Provinsi Kalimantan Tengah pada bulan Januari-Maret 2020.

\section{Jenis penelitian}

Penelitian ini merupakan penelitian deskriptif dengan pengambilan data secara retrospektif berdasarkan rekam medik pasien hipertensi. Teknik pengambilan sampel yang digunakan dalam penelitian ini ialah teknik purposive sampling.

\section{Populasi dan sampel penelitian}

Populasi dalam penelitian ini adalah semua rekam medik pasien hipertensi yang di rawat inap dan mendapat pengobatan di RSUD Sultan Imanuddin Pangkalan Bun 2018.
Sampel dari penelitian ini adalah rekam medik pasien hipertensi terpilih dari populasi yang memenuhi kriteria inklusi dengan jumlah sampel 85 pasien.

\section{Kriteria Inklusi dan Eksklusi Penelitian}

1) Kriteria Inklusi

Kriteria inklusi pada penelitian ini adalah :

a) Rekam medik dan resep pasien yang didiagnosis hipertensi

b) Usia pasien 25-60 tahun

2) Kriteria Eksklusi

Kriteria eksklusi pada penelitian ini adalah :

a) Rekam medik dan resep yang rusak, hilang atau tidak terbaca

b) Pasien yang meninggal dunia

\section{Pengumpulan Data}

Pengumpulan data dalam penelitian ini dilakukan di ruang rekam medik di RSUD Sultan Imanuddin Pangkalan Bun. Pengumpulan data dimulai dengan mencari data rekam medik pasien hipertensi dengan diagnosis utama hipertensi yang di rawat inap periode Januari sampai Desember 2018. Data yang diambil dibuat dalam tabulasi yang meliputi nama pasien, usia, jenis kelamin, diagnosis, terapi pengobatan, cara pemberian obat dan dosis obat.

\section{Analisis Data}

Data penggunaan obat antihipertensi pada pasien hipertensi di Instalasi Rawat Inap RSUD Sultam Imanuddin Pangkalan Bun periode 
Januari sampai Desember 2018 dianalisis deskriptip untuk menjelaskan kerasionalan pengobatan yang diberikan pada pasien hipertensi selama di rawat inap. Adapun standar pengobatan yang digunakan sebagai pembanding dalam penelitian ini yaitu Guideline Joint National Committee (JNC) VII dan JNC VIII serta Guideline European Society of Cardiology (ESC)/European Society Of Hypertension (ESH).

\section{HASIL DAN PEMBAHASAN Data Karateristik Responden}

Penelitian ini menggunakan data rekam medik pasien hipertensi yang dirawat selama bulan JanuariDesember 2018 diperoleh sampel sebanyak 85 pasien yang memenuhi kriteria inklusi dengan diagnosis hipertensi di Instalasi Rawat Inap RSUD Sultan Imanuddin Pangkalan Bun.

\section{Karateristik berdasarkan Jenis Kelamin}

Karakteristik jenis kelamin pasien hipertensi instalasi rawat inap di RSUD Sultan Imanuddin Pangkalan Bun selama periode Januari Desember 2018 yang menerima obat antihipertensi diperoleh data sebagaimana tertera pada tabel 1 .

Tabel 1. Distribusi Jenis kelamin pasien hipertensi

\begin{tabular}{c|c|c}
$\begin{array}{c}\text { Jenis } \\
\text { Kelamin }\end{array}$ & Jumlah & $\begin{array}{c}\text { Persentase } \\
(\mathbf{\%})\end{array}$ \\
\hline Laki-Laki & 20 & $23,5 \%$ \\
\hline Perempuan & 65 & $76,5 \%$ \\
\hline $\begin{array}{c}\text { Total } \\
\text { Berdasarkan }\end{array}$ & 85 & $100 \%$ \\
tabel di $\quad$ atas
\end{tabular}
menunjukkan bahwa sebagian besar jenis kelamin pasien hipertensi di Instalasi Rawat Inap RSUD Sultan
Imanuddin Pangkalan Bun 2018 yaitu diperoleh laki-laki lebih sedikit dibanding dengan perempuan dimana nilai perbandingan laki-laki sebanyak 20 orang $(23,5 \%)$ dan perempuan sebanyak 65 orang $(76,5 \%)$. Hal ini sesuai dengan $J N C$ VII dimana jenis kelamin perempuan lebih beresiko terpapar penyakit hipertensi sebesar 86-90\% di bandingankan jenis kelamin laki-laki sebesar $81-83 \%$. Penelitian ini juga telah dilakukan di RSUP Prof.Dr.R.D Kondou Manado menunjukkan bahwa pasien yang menderita penyakit hipertensi paling banyak perempuan dengan jumlah 58,97\% dan laki-laki dengan jumlah 41,03\% (Sumawa dkk, 2015).

Penyakit hipertensi berdasarkan jenis kelamin dapat dipengaruhi oleh faktor fisiologis (Zuraidah dkk, 2012). Karena faktor hormonal perempuan lebih banyak mengalami resiko hipertensi dari pada laki-laki (Irza, 2009). Hal ini sering terjadi karena perempuan yang mengalami menopause yang mengakibatkan terjadinya penurunan kadar esterogen sehingga kadar high density lipoprotein (HDL) yang berfungsi melindungi pembuluh darah dari kerusakan juga menurun oleh sebab itu terjadi peningkatan pelepasan renin sehingga memicu peningkatan tekanan darah (Aryzky dkk, 2018).

\section{Karateristik Berdasarkan Usia}

Data yang menunjukkan karateristik pasien hipertensi di Instalasi Rawat Inap RSUD Sultan Imanuddin Pangkalan Bun selama periode Januari-Desember 2018 yang menerima obat antihipertensi berdasarkan Usia. 
Tabel 2. Distribusi Usia Pasien Hipertensi.

\begin{tabular}{c|c|c}
$\begin{array}{c}\text { Usia } \\
\text { (Tahun) }\end{array}$ & Jumlah & $\begin{array}{c}\text { Presentase } \\
(\boldsymbol{\%})\end{array}$ \\
\hline $25-35$ & 6 & $7,06 \%$ \\
\hline $36-45$ & 11 & $12,94 \%$ \\
\hline $46-55$ & 35 & $41,2 \%$ \\
\hline $55-60$ & 33 & $38,8 \%$ \\
\hline Total & 85 & $100 \%$
\end{tabular}

Berdasarkan kelompok usia yang menderita hipertensi di peroleh kelompok usia 25-35 tahun sebanyak 6 penderita $(7,06 \%)$, kelompok usia 3645 tahun sebanyak 11 penderita (12,94\%), kelompok usia 46-55 tahun sebanyak 35 penderita $(41,2 \%)$, dan kelompok usia 55-60 tahun sebanyak 33 penderita $(38,8 \%)$. Pada umumnya semakin bertambahnya usia maka akan terjadi perubahan fisiologis dalam tubuh seperti penurunan elastisitas pembuluh darah dan perubahan struktur pembuluh darah besar yang menyebabkan lumen menjadi lebih sempit serta dinding pembuluh darah yang menjadi lebih kaku sehingga mengakibatkan tekanan darah meningkat (Dian Sa'idah dkk, 2019).

\section{Karateristik Berdasarkan Penyakit Penyerta}

Data yang menunjukkan karateristik pasien hipertensi di Instalasi Rawat Inap RSUD Sultan Imanuddin Pangkalan Bun selama periode Januari-Desember 2018 yang menerima obat antihipertensi berdasarkan penyakit penyerta.

Tabel 3. Distribusi penyakit penyerta pasien hiprtensi

\begin{tabular}{|c|c|c|c|}
\hline No & Jenis penyakit & Jumlah pasien & $\begin{array}{c}\text { Persentase } \\
(\%)\end{array}$ \\
\hline 1. & Hipertensi tanpa penyakit penyerta & 6 & $4,6 \%$ \\
\hline 2. & \multicolumn{3}{|l|}{ Hipertensi penyakit penyerta umum } \\
\hline & Vertigo & 22 & $16,9 \%$ \\
\hline & Dyspepsia & 15 & $11,5 \%$ \\
\hline & ISK & 8 & $6,2 \%$ \\
\hline & Vomiting & 7 & $5,4 \%$ \\
\hline & GERD & 5 & $3,8 \%$ \\
\hline & Cephalgia & 4 & $3,1 \%$ \\
\hline & Anemia & 4 & $3,1 \%$ \\
\hline & Saluran pencernaan & 3 & $2,3 \%$ \\
\hline & Asam urat & 2 & $1,5 \%$ \\
\hline & Febris & 2 & $1,5 \%$ \\
\hline & & 1 & $0,8 \%$ \\
\hline \multicolumn{4}{|c|}{\begin{tabular}{c}
\multicolumn{2}{c}{ Epitaksis } \\
Hipertensi dengan komplikasi
\end{tabular}} \\
\hline & Diabetes mellitus & 29 & $22,3 \%$ \\
\hline & Gagal jantung & 5 & $3,8 \%$ \\
\hline & Saluran pernafasan & 4 & $3,1 \%$ \\
\hline & Penyakit jantung & 3 & $2,3 \%$ \\
\hline & Gagal ginjal kronis & 3 & $2,3 \%$ \\
\hline & Kolesterol & 3 & $2,3 \%$ \\
\hline & Stroke & 2 & $1,5 \%$ \\
\hline & Jantung coroner & 1 & $0,8 \%$ \\
\hline & Penyakit jantung rematik & 1 & $0,8 \%$ \\
\hline tal & & 130 & $100 \%$ \\
\hline
\end{tabular}


Berdasarkan tabel 3. hipertensi tanpa penyakit penyerta sebanyak 6 pasien dengan persentase 4,6\%. Adapun penyakit penyerta yang paling banyak terjadi adalah Vertigo yaitu sebanyak 22 kasus (16,9\%), Dyspepsia sebanyak 15 kasus $(11,5 \%)$. Hipertensi yang terjadi dalam jangka waktu lama dan tidak terkontrol akan menyebabkan terjadinya kerusakan

\section{Karateristik Berdasarkan Jenis Hipertensi}

Data dari hasil yang menunjukkan karateristik pasien hipertensi di Instalasi Rawat Inap RSUD Sultan Imanuddin Pangkalan Bun selama periode Januari-Desember 2018 yang menerima obat antihipertensi berdasarkan jenis hipertensi.

Berdasarkan hasil penelitian diketahui bahwa dari 85 penderita hipertensi yang menjalani rawat inap di RSUD Sultan Imanuddin Pangkalan Bun pada tahun 2018, didapatkan penderita dengan hipertensi primer

\section{Karateristik Berdasarkan Penggunaan Obat Antihipertensi}

Data dari hasil penelitian yang menunjukkan penggunaan jenis dan golongan obat antihipertensi pada pasien hipertensi di Instalasi Rawat pada organ lain dapat menyebabkan komplikasi. Apabila telah terjadi komplikasi dapat menyebabkan kualitas hidup menjadi berkurang bahkan dapat menyebabkan kematian. Pasien hipertensi dengan komplikasi terbanyak adalah diabetes mellitus sebanyak 29 kasus (22,3\%), disusul penyakit gagal jantung sebanyak 5 kasus $(3,8 \%)$.

Tabel 4. Distribusi Jenis Hipertensi Pasien Hipertensi

\begin{tabular}{ccc} 
Diagnosa & $\begin{array}{c}\text { Jumlah } \\
\text { Pasien }\end{array}$ & $\begin{array}{c}\text { Persentase } \\
(\%)\end{array}$ \\
\hline $\begin{array}{c}\text { Hipertensi } \\
\text { Primer }\end{array}$ & 85 & $100 \%$ \\
$\begin{array}{c}\text { Hipertensi } \\
\text { Sekunder }\end{array}$ & 0 & $0 \%$ \\
\hline Total & 85 & $100 \%$ \\
\hline
\end{tabular}

sebanyak 85 orang (100\%). Hipertensi primer tidak diketahui penyebabnya secara pasti tetapi sering dikaitkan dengan faktor gaya hidup, Hipertensi primer merupakan 95\% dari seluruh kasus hipertensi (Kowalski, 2010). Inap RSUD Sultan Imanuddin Pangkalan Bun selama periode Januari-Desember 2018 yang menerima obat antihipertensi berdasarkan penggunaan obat antihipertensi.

\begin{tabular}{|c|c|c|c|c|c|}
\hline No & $\begin{array}{c}\text { Golongan } \\
\text { Obat }\end{array}$ & Jenis Obat & Jumlah Kasus & $\begin{array}{c}\text { Persentase } \\
\text { Jenis Obat }(\%)\end{array}$ & $\begin{array}{c}\text { Persentase } \\
\text { Gol. Obat } \\
(\%)\end{array}$ \\
\hline \multirow{2}{*}{1.} & \multirow[t]{2}{*}{ ARB } & Candesartan & 77 & $49 \%$ & \multirow{2}{*}{$50 \%$} \\
\hline & & Irbesartan & 1 & $1 \%$ & \\
\hline \multirow{3}{*}{2.} & \multirow[t]{3}{*}{$\mathrm{CCB}$} & Herbesser CD 200 & 43 & $27 \%$ & \multirow{3}{*}{$37 \%$} \\
\hline & & Amlodipin & 15 & $10 \%$ & \\
\hline & & Nifedipin & 1 & $1 \%$ & \\
\hline \multirow{2}{*}{3.} & \multirow{2}{*}{ DIURETIK } & Hidroklorotiazide & 7 & $4 \%$ & \multirow{2}{*}{$9 \%$} \\
\hline & & Furosemid & 7 & $4 \%$ & \\
\hline 4. & $\mathrm{ACE}$ & Captopril & 1 & $1 \%$ & $1 \%$ \\
\hline 5. & $\begin{array}{l}\text { BETA } \\
\text { BLOCKER }\end{array}$ & Bisoprolol, & 5 & $3 \%$ & $3 \%$ \\
\hline \multicolumn{2}{|c|}{ Total } & & 157 & $100 \%$ & $100 \%$ \\
\hline
\end{tabular}


Berdasarkan tabel.5 dapat dilihat hasil penelitian diperoleh bahwa pasien hipertensi yang berobat di Instalasi Rawat Inap RSUD Sultan Imanuddin Pangkalan Bun selama tahun 2018 obat antihipertensi paling banyak hingga yang paling sedikit digunakan pada pasien hipertensi yang di Rawat Inap yaitu golongan obat ARB sebanyak 78 pasien (50\%), CCB sebanyak 49 pasien (37\%), Diuretik sebanyak 14 pasien (9\%), Beta Blocker sebanyak 5 pasien (3\%), dan ACE Inhibitor sebanyak 1 pasien $(1 \%)$.

Obat golongan ARB merupakan obat yang banyak digunakan dalam peresepan jenis obat dari golongan

\section{Penggunaan Monoterapi dan Kombinasi Obat Antihipertensi}

Penggunaan monoterapi dan kombinasi obat antihipertensi pada pasien hipertensi di Instalasi Rawat
ARB yaitu candesartan, irbesartan, valsartan, dan telmisartan, mekanisme dari obat ini menghambat reseptor angiotensin II khususnya AT-1, Sebenarnya aksinya mirip dengan ACE Inhibitor, beda nya obat ini menghambat aktivasi angiotensin II terhadap reseptornya, sedangkan ACE Inhibitor menghambat produksi angiotensin II. Obat ini secara teori lebih menguntungkan dibanding ACE inhibitor karena tidak ada efek samping batuk keringnya. Selain itu, pembentukan angiotensin II sebenarnya tidak hanya tergantung oleh ACE Inhibitor, Namun juga oleh kinase, yang tidak dihambat ACE Inhibitor (Nugroho, 2015).

Inap RSUD Sultan Imanuddin Pangkalan Bun selama periode Januari-Desember 2018 dapat dilihat pada tabel 6.

Tabel 6. Distribusi Penggunaan Monoterapi dan Kombinasi Obat Antihipertensi.

\begin{tabular}{|c|c|c|c|c|}
\hline No & Golongan Obat & Jenis Obat & Kasus & Persentase \\
\hline \multicolumn{5}{|c|}{ Monoterapi Antihipertensi } \\
\hline 1. & ARB & Candesartan & 26 & $79 \%$ \\
\hline \multirow[t]{2}{*}{2.} & \multirow[t]{2}{*}{$\mathrm{CCB}$} & Amlodipin & 4 & $12 \%$ \\
\hline & & Herbesser CD & 2 & $6 \%$ \\
\hline 3. & Diuretik & Furosemid & 1 & $3 \%$ \\
\hline \multicolumn{3}{|c|}{ Total } & 33 & $100 \%$ \\
\hline \multicolumn{5}{|c|}{ Terapi 2 Kombinasi Antihipertensi } \\
\hline \multirow[t]{2}{*}{1.} & \multirow[t]{2}{*}{$\mathrm{ARB}+\mathrm{CCB}$} & Candesartan+Herbesser CD & 16 & $53 \%$ \\
\hline & & Herbesser CD+ Candesartan & 7 & $23 \%$ \\
\hline \multirow[t]{3}{*}{2.} & \multirow[t]{3}{*}{$\mathrm{CCB}+\mathrm{ARB}$} & Candesartan+Amlodipine & 2 & $6 \%$ \\
\hline & & Amlodipin+Candesartan & 2 & $6 \%$ \\
\hline & & Candesartan+Nifedipin & 1 & $3 \%$ \\
\hline \multirow[t]{2}{*}{3.} & \multirow{2}{*}{$\begin{array}{l}\text { ARB+Diuretik } \\
\text { Loop }\end{array}$} & Furosemide+Candesartan & 1 & $3 \%$ \\
\hline & & Candesartan+Hidroklortiazide & 2 & $6 \%$ \\
\hline \multicolumn{3}{|c|}{ Total } & 31 & $100 \%$ \\
\hline \multicolumn{5}{|c|}{ Terapi 3 Kombinasi Atihipertensi } \\
\hline \multirow[t]{3}{*}{1.} & \multirow[t]{3}{*}{$\begin{array}{l}\text { ARB+CCB+Diure } \\
\text { tik Loop }\end{array}$} & $\begin{array}{l}\text { Candesartan+Herbesser+Hidroklor } \\
\text { tiade }\end{array}$ & 4 & $25 \%$ \\
\hline & & $\begin{array}{l}\text { Herbesser } \\
\text { CD+Furosemid+Candesartan }\end{array}$ & 1 & $6 \%$ \\
\hline & & $\begin{array}{l}\text { Candesartan+Herbesser } \\
\text { CD+Furosemid }\end{array}$ & 1 & $6 \%$ \\
\hline
\end{tabular}




\begin{tabular}{|c|c|c|c|c|}
\hline & & $\begin{array}{l}\text { Herbesser } \\
\text { CD+Candesartan+Furosemid }\end{array}$ & 1 & $6 \%$ \\
\hline \multirow[t]{2}{*}{2.} & \multirow[t]{2}{*}{$\mathrm{ARB}+\mathrm{CCB}$} & $\begin{array}{l}\text { Candesartan+Herbesser } \\
\text { CD+Amlodipin }\end{array}$ & 3 & $19 \%$ \\
\hline & & $\begin{array}{l}\text { Herbesser } \\
\text { CD+Candesartan+Amlodipin }\end{array}$ & 2 & $13 \%$ \\
\hline \multirow[t]{3}{*}{3.} & \multirow[t]{3}{*}{$\begin{array}{l}\mathrm{ARB}+\mathrm{CCB}+\beta- \\
\text { Blocker }\end{array}$} & $\begin{array}{l}\text { Candesartan+Herbesser } \\
\text { CD+Bisoprolol }\end{array}$ & 2 & $13 \%$ \\
\hline & & $\begin{array}{l}\text { Candesartan+Bisoprolol+Amlodip } \\
\text { in }\end{array}$ & 1 & $6 \%$ \\
\hline & & $\begin{array}{l}\text { Herbesser } \\
\text { CD+Candesartan+Bisoprolol }\end{array}$ & 1 & $6 \%$ \\
\hline \multicolumn{3}{|c|}{ Total } & 12 & $100 \%$ \\
\hline \multicolumn{5}{|c|}{ Terapi 4 Kombinasi Antihipertensi } \\
\hline 1. & $\begin{array}{l}\text { Diuretik+ARB+A } \\
\text { CE-I+ARB }\end{array}$ & $\begin{array}{l}\text { Furosemid+Candesartan+Captopri } \\
\text { 1+Herbesser CD }\end{array}$ & 1 & $50 \%$ \\
\hline 2. & $\begin{array}{l}\mathrm{CCB}+\mathrm{ARB}+\text { Diure } \\
\text { tik }\end{array}$ & $\begin{array}{l}\text { Amlodipin+Candesartan+Hidriklo } \\
\text { rtiazide+Furosemid }\end{array}$ & 1 & 50 \\
\hline \multicolumn{3}{|c|}{ Total } & 2 & $100 \%$ \\
\hline
\end{tabular}
antihipertensi yang paling banyak yaitu golongan ARB candesartan 26 kasus dengan persentase (79\%). Penggunaan kombinasi 2 obat antihipertensi ini bertujuan untuk mempertahankan tekanan darah yang memiliki tempat aksi dan golongan yang berbeda serta untuk meningkatkan kepatuhan pasien hipertensi dalam mengonsumsi obat (Skolnik, 2000). Sedangkan obat yang paling banyak digunakan sebagai terapi kombinasi sesuai golongannya dan berdasarkan terapi kombinasi.

Pada terapi 2 kombinasi antihipertensi yang paling banyak digunakan adalah golongan $\mathrm{ARB}+\mathrm{CCB}$ yaitu Candesartan+Herbesser CD 16 kasus dengan persentase $(51,6 \%)$. Untuk terapi 3 kombinasi antihipertensi yang
+Hidroklortiazide 4 kasus dengan persentase (25\%). Golongan obat ARB dan CCB bekerja dengan cara meningkatkan kerja suatu obat kemudian dikombinasikan diuretik untuk mengatur keseimbangan cairan dalam tubuh, sehingga mengurangi beban jantung memompa aliran darah (Supadmi, 2011).

\section{Dosis Antihipertensi}

Berdasarkan hasil penelitian dosis antihipertensi pada pasien hipertensi di Instalasi Rawat Inap RSUD Sultan Imanuddin Pangkalan Bun selama periode Januari-Desember 2018. 
Tabel 7. Distribusi Dosis Antihipertensi Pasien Hipertensi

\begin{tabular}{c|c|c|c|c} 
No & Jenis Obat & Jenis Sediaan & Jumlah Pasien & Dosis Pasien \\
\hline 1. & Candesartan & Per Oral & 77 & $8-16 \mathrm{mg}$ \\
\hline 2. & Irbesartan & Per Oral & 1 & $300 \mathrm{mg}$ \\
\hline 3. & Herbesser CD & Per Oral & 43 & $200 \mathrm{mg}$ \\
\hline 4. & Amlodipin & Per Oral & 15 & $10 \mathrm{mg}$ \\
\hline 5. & Nifedipin & Per Oral & 1 & $10 \mathrm{mg}$ \\
\hline 6. & Hidroklorothiazid & Per Oral & 7 & $25 \mathrm{mg}$ \\
\hline 7. & Furosemid & Intravena & 7 & $20-40 \mathrm{mg}$ \\
\hline 8. & Captopril & Per Oral & 1 & $25 \mathrm{mg}$ \\
\hline 9. & Bisoprolol & Per Oral & 5 & $2,5-10 \mathrm{mg}$ \\
\hline
\end{tabular}

Pada penelitian berdasarkan dosis antihipertensi menunjukan bahwa dari 157 total item obat yang digunakan, diperoleh tablet candesartan dengan dosis 8-16 mg sekali sehari, tablet irbesartan dengan dosis $300 \mathrm{mg}$ sekali sehari, tablet herbesser CD 200 dengan dosis $200 \mathrm{mg}$ sekali sehari, tablet amlodipine dengan dosis $10 \mathrm{mg}$ sekali sehari, tablet nifedipin dengan dosis $10 \mathrm{mg}$ sekali sehari, tablet

\section{Evaluasi Kerasionalan Penggunaan Antihipertensi}

Evaluasi kerasionalan penggunaan obat antihipertensi dilakukan terhadap 85 dari data rekam medik pasien penderita hipertensi yang di Instalasi Rawat Inap RSUD Sultan Imanuddin Pangkalan Bun selama Januari- hidroklorotiazide dengan dosis $25 \mathrm{mg}$ sekali sehari, injeksi furosemid dengan dosis $20-40 \mathrm{mg}$ sekali sehari, tablet captopril dengan dosis $25 \mathrm{mg} 2$ kali sehari, tablet bisoprolol dengan dosis 2,5-10 mg sekali sehari. Sebagian besar dosis obat antihipertensi serta frekuensi pemberian yang utama telah sesuai dengan acuan standar dosis lazim dari Joint National Committee VII untuk penyakit hipertensi.

Desember 2018. Evaluasi kerasionalan dilakukan dengan beberapa kriteria kerasionalan, yaitu tepat pasien, tepat indikasi, tepat obat dan tepat dosis (Kemenkes RI, 2011).

Tabel 8. Kerasionalan penggunaan obat antihipertensi

\begin{tabular}{l|c|c|c|c}
\multirow{2}{*}{\multicolumn{2}{c}{ Kriteria kerasionalan }} & \multicolumn{2}{|c|}{ Jumlah penggunaan } & \multicolumn{2}{c}{$\begin{array}{c}\text { Persentase } \\
\text { (\%) }\end{array}$} \\
\cline { 2 - 5 } & Tepat & Tidak tepat & Tepat & Tidak tepat \\
\hline Tepat Pasien & 80 & 5 & $94,1 \%$ & $5,9 \%$ \\
\hline Tepat Indikasi & 83 & 2 & $98 \%$ & $2 \%$ \\
\hline Tepat Obat & 85 & 0 & $100 \%$ & $0 \%$ \\
\hline Tepat Dosis & 85 & 0 & $100 \%$ & $0 \%$ \\
\hline
\end{tabular}

\section{a) Tepat Pasien}

Dalam penelitian ini evaluasi ketepatan pasien dilakukan dengan membandingkan kontraindikasi obat yang diberikan kepada pasien dan jika ada riwayat alergi yang tercantum pada rekam medis. Maka apabila obat yang diberikan kepada pasien tidak berkontraindikasi dengan 
keadaan pasien dan tidak ada riwayat alergi maka pengobatan dapat dikatakan sebagai tepat pasien. Berdasarkan penelitian yang telah dilakukan terhadap 85 data rekam medik pasien hipertensi di Instalasi Rawat Inap RSUD Sultan Imanuddin Pangkalan Bun periode JanuariDesember 2018. Didapatkan nilai dari ketepatan pemilihan obat antihipertensi berdasarkan tidak tepat pasien sebanyak 5 kasus $(5,9 \%)$ dan tepat pasien yaitu 80 kasus $(94,1 \%)$.

Ketidaktepatan pasien pada penelitian ini disebabkan adanya pemberian obat golongan CCB yaitu herbesser $C D$ dimana obat ini kontraindikasi dengan penyakit gagal jantung karena memiliki efek inotropik negatif dan bisa menyebabkan perburukan pada gagal jantung. Namun obat ini dapat digunakan pada gagal jantung diastolik. Hasil dari penelitian ini tidak sejalan dengan penelitian yang telah dilakukan Sumawa (2015) tentang evaluasi kerasionalan berdasarkan ketepatan pasien yang dirawat di RSUP Prof. Kandou Manado yaitu sebanyak $100 \%$ dengan jumlah sampel 39 rekam medik dan menggunakan standar JNC VII.

\section{b) Tepat Obat}

Evaluasi ketepatan obat dinilai berdasarkan kesesuaian pemilihan terapi baik tunggal maupun kombinasi dengan mempertimbangkan diagnosis yang tertulis dalam rekam medik dan dibandingkan dengan standar yang digunakan Joint National Committe VII. Pada penilitian ini diketahui bahwa dari 85 rekam medik pasien hipertensi sebanyak 2 rekam medik (2\%) dinilai tidak tepat pemilihan obat dan 83 rekam medik (98\%) dinilai tepat pemilihan obat.

Adapun ketidaktepatan obat pada penilitian ini adanya kombinasi antara candesartan+irbesartan dimana kedua obat ini merupakan satu golongan ARB karena efek samping dari obat ini dapat menyebabkan gangguan saluran pernafasan, sakit punggung, gangguan saluran cerna, kelelahan dan neutropenia (Sweetman, 2009). Sedangkan kombinasi Herbesser CD+Amlodipin merupakan satu golongan CCB dimana obat ini memiliki efek samping yaitu bisa menyebabkan konstipasi (Lacy, 2008). Hal ini dinilai tidak tepat dikarenakan kombinasi obat antihipertensi sebaiknya dipilihkan dari golongan yang berbeda, dimulai dari dosis yang lebih rendah untuk meninggkatkan keefektifan dan mengurangi resiko efek samping yang tidak diinginkan kepada pasien. (Dian Sa'idah, 2019).

\section{c) Tepat Indikasi}

Evaluasi ketepatan indikasi di lihat perlu tidaknya pasien diberi obat anti hipertensi berdasarkan 
tekanan darah pasien > 140/90 mmHg. Penggunaan obat dikatagorikan tepat indikasi apabila obat yang diresepkan sesuai dengan di agnosa adanya penyakit hipertensi. Berdasarkan penelitian yang telah dilakukan terhadap 85 data rekam medik pasien hipertensi di Instalasi Rawat Inap RSUD Sultan Imanuddin Pangkalan Bun periode JanuariDesember 2018. Didapatkan nilai dari ketepatan pemilihan obat antihipertensi berdasarkan tepat indikasinya yaitu mencapai $100 \%$. Penggunaan obat antihipertensi dikategorikan tepat indikasi karena obat antihipertensi ACEI, ARB, CCB, Diuretik, dan $\beta$-Blocker diberikan kepada pasien hipertensi stage 1, stage 2, ataupun hipertensi dengan komplikasi (Dian Sa'idah, 2019).

\section{d) Tepat Dosis}

Pemberian dosis obat antihipertensi pada pasien dalam

\section{KESIMPULAN}

1) Pasien hipertensi di Instalasi Rawat Inap RSUD Sultan Imanuddin Pangkalan Bun sebagian besar adalah perempuan (76,5\%), Usia 46-55 tahun (41,2\%), Penyakit dengan komplikasi Diabetes mellitus sebanyak 29 pasien $(22,3 \%)$, jenis hipertensi primer sebanyak 85 pasien (100\%) serta Golongan obat yang paling banyak digunakan untuk pasien hipertensi penelitian ini dapat dikatakan tepat dosis apabila obat antihipertensi berada pada rentang dosis minimal dan dosis perhari yang dianjurkan dalam guidline Joint National Comitte VII. Berdasarkan penelitian yang telah dilakukan terhadap 85 data rekam medik pasien hipertensi di Instalasi Rawat Inap RSUD Sultan Imanuddin Pangkalan Bun periode JanuariDesember 2018. Didapatkan nilai dari ketepatan pemilihan obat antihipertensi berdasarkan tepat indikasinya yaitu mencapai $100 \%$. Hal ini sejalan dengan penelitian yang telah dilakukan oleh Ira Yosida (2016) menunjukkan nilai $100 \%$ karena ketepatan penggunaan dosis obat antihipertensi yang sesuai pada pasien rawat inap bangsal bakung Rumah Sakit Panembahan Senopati Bantul Yogyakarta periode agustus 2015.

adalah Golongan ARB yaitu candesartan (49\%).

2) Evaluasi kerasionalan penggunaan obat antihipertensi di Instalasi Rawat Inap RSUD Sultan Imanuddin Pangkalan Bun selama bulan Januari-Desember 2018 dapat dilihat berdasarkan guideline Joint National Committe. (JNC) dengan kriteria tepat pasien sebanyak $94,1 \%$, tepat obat sebanyak 99\% tepat indikasi sebanyak $100 \%$, dan tepat dosis sebanyak $100 \%$. 


\section{SARAN}

1. Bagi Institusi Rumah Sakit, diharapkan lebih meningkatkan pemantauan terhadap kelengkapan rekam medis pasien, penulisan lebih jelas demi mempermudah mengetahui riwayat penyakit dan pengobatan pasien serta dasar pertimbangan penentuan terapi sehingga dapat digunakan sebagai bahan penelitian selanjutnya.

2. Bagi masyarakat, diharapkan untuk memeriksakan tekanan darah agar dapat mengantisipasi bila terjadi hipertensi terutama pada lansia, cara yang baik untuk menghindari hipertensi ialah

DAFTAR PUSTAKA

Aryzki, S., 2016, Pengaruh Brief Counseling Terhadap Aktivitas Fisik pada Pasien Hipertensi di RSUD dr. H. Moch Ansari Saleh Banjarmasin, Jurnal Sains Farmasi \& Klinis, Vol 2, No.5

Bryan Williams, dkk.(2018). ESC/ESH Guideline For The Management Of Arterial Hypertension. European Heart Journal. Institut Of Cardiovascular Science.

Cippole R.J. Strand L.M. dan Morley P.C. (2012). Pharmaceutical Care Practice: PatientCentered Approach to Medication Management3rd edition. McGraw Hill. New York City. http://health.kompas.com/re ad/2013/04/1404008/Pederit a Hipertensi Terus dengan mengubah gaya hidup menjadi lebih sehat, mengatur pola makan yang baik dan aktivitas fisik yang cukup seperti berolahraga, mengatur diet atau pola makan rendah garam, rendah kolesterol serta lemak jenuh, meningkatkan konsumsi buah dan sayuran, tidak mengkonsumsi alkohol dan merokok.

3. Bagi peneliti selanjutnya, perlu dilakukan penelitian tentang kepatuhan dan kualitas hidup pasien dalam penggunaan obat antihipertensi agar dapat menurunkan resiko terjadinya komplikasi

Meningkat Tanggal Akses 21 oktober 2019

Joint National Comitee (JNC). (2014). The eight Report of the Joint National Comitee on Prevention, Detecton, Evaluation and Treatment of High Blood Pressure. Department of Healt and Human Service, National Institute of Health

Kowalski, R., 2010, Terapi Hipertensi. Terjemahan: Rani S.Bandung: Qanita Zulkeflie, NASB 2011

Natalia, D., Petrus Hasibuan, dan Hendro. (2014). Hubungan Obesitas dengan Hipertensi pada Penduduk Kecamatan Sintang, Kalimantan Barat. eJurnal Kedokteran Indonesia Vol 2 No. 3.

Nugroho, Agung Endro. 2015. Farmakologi. Cetakan V. Yogyakarta: Pustaka Pelajar 
Putri Astana, S.L., Satriyasa, K.B., dan Jawi, M. I. (2016). Gambaran Pola Penggunaan Obat Antihipertensi Pada Pasien Hipertensi Di Instalasi Rawat Inap Rsup Sanglah Denpasar Tahun 2016. Jurnal Medika Udayana, Vol.8 No.6

Sa'idah, D. dkk., (2019). Evaluasi Rasionalitas Penggunaan Obat Antihipertensi di Instalasi Rawat Jalan RSUD Dr. Soengiri Lamongan Periode Tahun 2017. Program Studi Farmasi. Fakultas Kedokteran dan Ilmu Kesehatan. Univ. Islam Negeri Maulana Malik Ibrahim. Malang. EISSN:2614-6495.

Vol.17.No.1

Skolnik, N. S., J. D. Beck, and M. Clark., (2000). Combination Antihypertensive Drugs: Recommendations for Use. Am Fam Physician, 61 (10): 3049-3056.

Sumawa, P.M.R., Wullur, A.C., Yamlean, P.V.Y., 2015, Evaluasi Kerasionalan Penggunaan Obat Antihipertensi pada Pasien
Hipertensi Rawat Inap di RSUP Prof. Dr. R. D. Kandou Manado Periode Januari-Juni 2014. Jurnal Ilmiah Farmasi. Vol.04, no.3

Supadmi, Woro., (2011). Evaluasi Penggunaan Obat Antihipertensi Pada Pada Pasien Gagal Ginjal Kronik Yang Menjalani Hemodialisa. Fakultas Farmasi UAD. Yogyakarta.

Widiyani, R., (2013). Penderita Hipertensi Terus Meningkat.

Yosida, I. (2016). Efektifitas

Penggunaan Obat Antihipertensi di Instalasi Rawat Inap Bangsal Bakung RSUD Panembahan Senopati Bantul Periode Agustus 2015. Skripsi.

Fakultas Farmasi Universitas Sanata Dharma Yogyakarta.

Zuraidah, Maksuk, Nadi. (2012). Analisa faktor resiko hipertensi pada masyarakat di kecamatan kemuning kota Palembang tahun 2012 [karya ilmiah]. Politeknik Kesehatan Palembang. 